\title{
Effect of Brucella Infection on Reproduction Conditions of Female Breeding Cattle and Its Public Health Significance in Western Tigray, Northern Ethiopia
}

\author{
Mekonnen Haileselassie, ${ }^{1}$ Shewit Kalayou, ${ }^{2,3}$ Moses Kyule, ${ }^{4}$ Mekonnen Asfaha, ${ }^{5}$ \\ and Kelay Belihu ${ }^{4}$ \\ ${ }^{1}$ Tigray National Regional State Science and Technology Agency, P.O. Box 349, Mekelle, Ethiopia \\ ${ }^{2}$ Department of Pathobiology and Infectious Diseases, College of Veterinary Medicine, Mekelle University, \\ P.O. Box 3189 Mekelle, Ethiopia \\ ${ }^{3}$ Department of Production Animal Clinical Sciences, Norwegian School of Veterinary Science, \\ P.O. Box 8146 Dep N-0033, Ullevålsveien 72 Oslo, Norway \\ ${ }^{4}$ Faculty of Veterinary Medicine, Addis Ababa University, P.O. Box 34, Debre Zeit, Ethiopia \\ ${ }^{5}$ Section for Communicable Diseases, Kahsay Abera Hospital, P.O. Box 21 Humera, Ethiopia
}

Correspondence should be addressed to Shewit Kalayou, skalayout@gmail.com

Received 8 March 2011; Revised 25 April 2011; Accepted 25 May 2011

Academic Editor: Paulo M. Roehe

Copyright (c) 2011 Mekonnen Haileselassie et al. This is an open access article distributed under the Creative Commons Attribution License, which permits unrestricted use, distribution, and reproduction in any medium, provided the original work is properly cited.

\begin{abstract}
The most common clinical manifestations of brucellosis in livestock are associated with reproduction. This paper reports the result of a cross-sectional study conducted between October, 2007 and April, 2008 in Western Tigray, North Ethiopia, with the objectives of assessing the effect of Brucella infection on reproduction conditions of female breeding bovine and to explore the presence of Brucella seroreactors in vulnerable humans. A total of 1,354 and 246 sera were collected from female cattle and humans, respectively. The sera were screened using Rose Bengal plate test (RBPT), and positive samples were confirmed by complement fixation test (CFT). Reproductive conditions for female cattle and risk to human brucellosis seropositivity were tested by using logistic regression analysis. The result indicated that the overall prevalence in female cattle was $6.1 \%$. The study showed $1.2 \%$ prevalence among human risk groups, all of which were herdsmen. Logistic regression identified parity status, calving interval, abortion history, and abortion period were significantly associated with seropositivity. The association was not significant with reproductive status and parity number. Proper hygienic practices and team work between veterinary and health personnel should improve the efforts to combat disease transmission.
\end{abstract}

\section{Introduction}

The proportion of people relying on livestock for some or their entire livelihood is very high in Africa, ranging from 20 to over $90 \%$, depending on the livestock production system and country in focus [1]. In rural parts of Ethiopia, for instance, human life is highly associated with livestock population in the different livestock production systems [2]. In both pastoral and mixed livestock production systems people live very closely with livestock having a high incidence of brucellosis and thus, are at higher risk of acquiring the infection [3].
Brucellosis in cattle is endemic in Ethiopia. Several studies were conducted in local and crossbreed animals, and seroprevalence of brucellosis in cattle up to $22 \%$ were recorded [2-8]. Human brucellosis has also been indicated to exist in Ethiopia [9-11]. But the occurrence in human population of the Western Tigray Regional State remained unknown. It is known that this part of the region is home for barka cattle breed $[8,12]$.

Barka cattle breed (commonly known as begait) is an indigenous zebu breed inhabiting Eastern Sudan, Southern Eritrea, and Northwest Ethiopia [12]. The breed is mainly known for its higher milk yield (yields up to $12 \mathrm{~L} /$ day), 


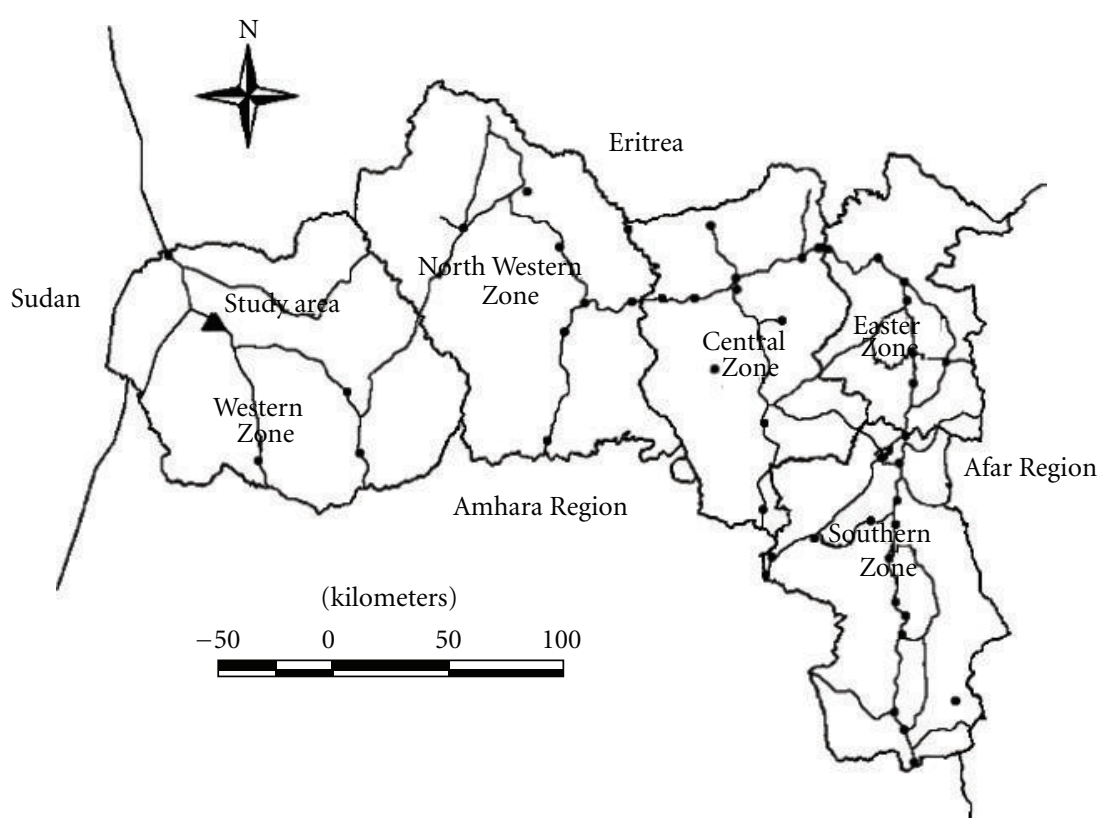

Figure 1: Map of Tigray regional state showing the study area.

meat, and traction power. The breed has been distributed in various areas of the region with the aim of boosting milk production. Despite all the merits of the breed, higher Brucella seroprevalence (7.2\%) was reported [8], causing skepticism among farmers about the perceived benefits of the breed. Many of the factors associated with an increased seroprevalence of brucellosis in some of the indigenous breeds of cattle were reported previously [8]. It has been stated that the most common clinical manifestations of brucellosis in livestock are associated with reproduction, mainly abortion, birth of weak offspring, and infertility $[2,13]$. Studies on the effect of Brucella infection on reproductive conditions are rare in the country justifying the need for further studies. As brucellosis is a zoonotic disease, capable of infecting humans by consumption of nonpasteurized milk and contact with infected animals, the epidemiological investigations should also constitute the extent to which humans are involved in the epidemiological dynamics. The objectives of the study were therefore to investigate the effect of Brucella infection on some of the reproductive conditions of indigenous breeding female cattle and to explore the presence of human seroreactors among vulnerable groups.

\section{Materials and Methods}

2.1. Study Area. The study was conducted in the Western Zone of Tigray Regional State, North West Ethiopia. Its geographical location is $13^{\circ} 42^{\prime}$ to $14^{\circ} 28^{\prime}$ north latitude and $36^{\circ} 23^{\prime}$ to $37^{\circ} 31^{\prime}$ east longitude. The study area is bordered north by Eritrea, south by Gonder (Amhara region), and east by Tahtai Adiabo and west by Sudan (Figure 1). The altitude ranges from 560 to 2800 meters above sea level. The Western Zone is one of the five administrative zones in the Tigray Regional State and has three districts, namely, Welkait, Tsegede, and Humera with distance range of 580$750 \mathrm{~km}$ from Mekelle, the capital city of Tigray. The study area represents a remote, tropical climate where extensive agriculture is performed manually by large numbers of migrant laborers. Throughout the zone, livestock agriculture is the predominant economic activity with about $95 \%$ of the total population engaged directly or indirectly in it. Main cattle breeds raised in the Western Zone are the local arado and barka/begait cattle. Semi-intensive production is practiced in Humera district, which is more urban, while extensive production system is dominant in the Welkait and Tsegede districts. The study area's position near the Eritrean and Sudanese borders means that it is a transit point for cross-border trade and traffic.

2.2. Cattle Samples. A cross-sectional study was conducted between October 2007 to February 2008 to determine Brucella seroprevlence and to assess the effect of Brucella infection on reproduction parameter of female cattle using serological procedures and questionnaire survey. Structured and pretested questionnaires were also used to interview livestock owners to gather relevant information on the management factors. The true representatives of the study population were selected by combination of simple random and two-stage cluster sampling methods where herds of cattle were considered as clusters. Details of the sampling strategy were described previously [8]. Briefly, a complete list of the peasant associations (PAs) was obtained from the agriculture offices of the respective districts from which forty-two PAs were selected from a total of 69 . The average herd size in the extensive system was four cattle. Access to at least one seasonal road was considered for the selection PAs. Two hundred and ten herds with a minimum herd size of four 
TABLE 1: Summary number of breeding female indigenous cattle sampled from three districts of Western Tigray, North Western Ethiopia, October 2007 to February 2008.

\begin{tabular}{lccc}
\hline District & Total animals sampled & Total females sampled & Proportion $(\%)$ \\
\hline Humera & 1,220 & 909 & 74.5 \\
Welkait & 220 & 138 & 62.7 \\
Tsegede & 528 & 307 & 58.1 \\
\hline Total & 1,968 & 1,354 & 68.8 \\
\hline
\end{tabular}

cattle were tested from the extensive production system. These comprised a total of 848 cattle. In the semi-intensive production system, a total of 110 herds with a minimum herd size of 10 cattle were examined adding up to 1,120 animals. For the purpose of the present study, we further investigated 1,354 breeding female (Primiparous and above) cattle subpopulation. Female cattle aged three and above years were the target animals. Summary of total number of sampled animals per each district is indicated in Table 1.

2.3. Public Health Survey. For public health study, human blood samples were collected from potential risk groups for brucellosis from October 2007 to February 2008. Occupational workers, notably cattle attendants, abattoir workers, butchers, veterinarians, and other animal health assistants were identified first and then fully informed by the health posts. Blood samples were collected from apparently healthy volunteers in collaboration with Zonal Health Offices and Kahsay Abera Hospital located in Humera. The procedure was approved by institutional ethical review board of Addis Ababa University and by the Regional Health Bureau (15/334/2007). Information was collected using a pretested questionnaire about the possible risk factors associated with human Brucella infections such as assisting removal of retained fetal membranes and drinking raw milk. All the tested individuals were interviewed in their native language (Tigrigna). The interview and serum collection were carried out in parallel. The sample size for estimating the seroprevalence of brucellosis in human risk groups was determined by standard procedures as described in [14]. The following formula was used for calculating the sample size; $N=\left(1.96^{2} \times p_{\exp }\left[1-p_{\exp }\right]\right) / d^{2}$ where, $N=$ required sample size, $p_{\exp }=$ expected prevalence, $d=$ desired absolute precision. An expected prevalence of $20 \%$ and $5 \%$ desired absolute precision with a $95 \%$ assumed confidence level was used and a sample size of 246 people was obtained.

2.4. Sera Collection and Testing. About $10 \mathrm{~mL}$ of whole blood sample was collected from the jugular vein, using plain vaccutainer tubes and needles, from each cattle aged above six months and with no history of vaccination for brucellosis. On the other hand, about $5 \mathrm{~mL}$ of blood was collected from the elbow veins of potential human risk groups. Each sample tube was labeled using codes which are specific to the individual sample. The tubes were tilted on a table overnight at room temperature to allow clotting of the blood. Serum was collected either passively by decanting or after centrifugation of the blood samples at 2,500 rpm for $5 \mathrm{~min}$ sera had not clearly separated from the blood clot. The serum was stored at $-20^{\circ} \mathrm{C}$ until tested serologically by Rose Bengal plate test (RBPT) and/or complement fixation test (CFT). RBPT was used as a screening test for detection of Brucella antibodies as described earlier by [15] using Brucella abortus antigen (Institute Pourquir, Montpellier, France). Samples giving positive results were then confirmed by the CFT. The RBPT was carried out at the Regional Veterinary Laboratory while the CFT was undertaken at the National Veterinary Institute, Department of Immunology, DebreZeit. Preparation of the CFT reagents was performed according to OIE protocols [16]. As for the interpretation of test results, positive reactions were indicated by sedimentation of sheep red blood cells (SRBC) and absence of hemolysis. Negative reactions were revealed by hemolysis of SRBC. Sera with strong reaction, more than $75 \%$ fixation of complement at a dilution of $1: 10$ and at least with $50 \%$ fixation of complement at a working dilution $(1: 5)$ was classified as positive [17].

2.5. Data Management and Analyses. Data obtained from both serological tests and questionnaire survey were stored in Microsoft Excel spreadsheet (Microsoft Corp.). These data were analyzed by descriptive statistics univariable and multivariable regression using the SPSS 15 statistical package [18]. Animal or human sera tested positive to CFT were defined as seropositive. Female cattle were categorized into four groups based on their reproductive status: heifer, pregnant, lactating, and dry. Cattle at different parity numbers were also grouped into three categories: cows with no parity, two parities, and with more than two. Pregnant cattle $(n=244)$ were categorized into groups on the basis of their stage of gestation. The first group comprised cattle below five months of pregnancy $(n=146)$ and the other group having cattle with equal to and above five months of pregnancy $(n=98)$. The remaining 1110 female cattle were nonpregnant. Information on cattle reproductive status, parity, pregnancy status, and stage of gestation were obtained from the owners. Univariable logistic regression was applied to answer the question of whether or not there is a significant association between seropositivity and reproductive conditions. To see the effect of Brucella seropositivity on these reproductive conditions that may be influenced by the presence of other factors through effect modifications (i.e., interactions), all the significant variables 
TABLE 2: Summary results of the univariable and multivariable logistic regression (LR) analyses of reproductive conditions with dependent Brucella seropositivity in female cattle in Western Tigray, North West Ethiopia. OR: odds ratio, CI: confidence interval, October 2007 to February 2008.

\begin{tabular}{|c|c|c|c|c|c|c|c|c|c|c|c|}
\hline \multirow[t]{3}{*}{ Reproductive conditions } & \multirow[t]{3}{*}{ Category level } & \multirow[t]{3}{*}{$n$} & \multirow[t]{3}{*}{ Prevalence } & \multicolumn{4}{|c|}{ Univariable LR analysis result } & \multicolumn{4}{|c|}{ Multivariable LR analysis results } \\
\hline & & & & \multirow{2}{*}{$P$-value } & \multirow{2}{*}{ OR } & \multicolumn{2}{|c|}{$95 \% \mathrm{CI}$ of OR } & \multirow{2}{*}{$P$-value } & \multirow{2}{*}{ OR } & \multicolumn{2}{|c|}{$95 \% \mathrm{CI}$ of $\mathrm{OR}$} \\
\hline & & & & & & Lower & Upper & & & Lower & Upper \\
\hline \multirow{5}{*}{ Reproductive status } & Heifer & 506 & 3.7 & 0.021 & & & & \multirow{5}{*}{0.953} & \multirow{5}{*}{0.991} & \multirow{5}{*}{0.742} & \multirow{5}{*}{1.324} \\
\hline & Pregnant & 244 & 8.6 & 0.007 & 2.414 & 1.272 & 4.580 & & & & \\
\hline & Lactating & 286 & 5.6 & 0.229 & 1.519 & 0.768 & 3.003 & & & & \\
\hline & Dry & 318 & 8.2 & 0.008 & 2.282 & 1.241 & 4.196 & & & & \\
\hline & Subtotal & 1,354 & 6.1 & - & - & - & - & & & & \\
\hline \multirow{4}{*}{ Parity status } & No parity & 578 & 3.8 & 0.011 & & & & \multirow{4}{*}{0.042} & \multirow{4}{*}{1.491} & \multirow{4}{*}{1.014} & \multirow{4}{*}{2.192} \\
\hline & One or two & 274 & 6.9 & 0.049 & 1.883 & 1.001 & 3.541 & & & & \\
\hline & More than two & 502 & 8.2 & 0.003 & 2.248 & 1.320 & 3.828 & & & & \\
\hline & Subtotal & 1,354 & 6.1 & 一 & 一 & - & 一 & & & & \\
\hline \multirow{4}{*}{ Stage of pregnancy } & Non pregnant & 1,110 & 5.5 & 0.0024 & - & - & - & \multirow{4}{*}{$>0.0001$} & \multirow{4}{*}{2.96} & \multirow{4}{*}{1.86} & \multirow{4}{*}{3.49} \\
\hline & $<5$ months & 146 & 6.2 & 0.082 & 2.92 & 0.98 & 8.27 & & & & \\
\hline & $\geq 5$ months & 98 & 12.2 & $>0.0001$ & 7.85 & 2.98 & 20.79 & & & & \\
\hline & Subtotal & 1,354 & 6.1 & - & - & - & - & & & & \\
\hline
\end{tabular}

TABLE 3: Univariable logistic regression analyses of abortion related factors with dependent Brucella seropositivity in cows in Western Tigray, North West Ethiopia, October 2007 to February 2008.

\begin{tabular}{|c|c|c|c|c|c|c|c|}
\hline \multirow{2}{*}{ Status of abortion } & \multirow{2}{*}{ Category level } & \multirow{2}{*}{$n$} & \multirow{2}{*}{ Prevalence (\%) } & \multirow{2}{*}{$P$-value } & \multirow{2}{*}{ OR } & \multicolumn{2}{|c|}{$95 \%$ CI of OR } \\
\hline & & & & & & Lower & Upper \\
\hline \multirow{2}{*}{ Abortion } & Absent & 718 & 6.7 & & - & - & - \\
\hline & Present & 58 & 20.7 & 0.001 & 3.641 & 1.809 & 7.330 \\
\hline \multirow{2}{*}{ Abortion frequency } & Only once & 48 & 22.9 & & - & - & - \\
\hline & More than one & 10 & 10 & 0.359 & 0.374 & 0.043 & 3.283 \\
\hline \multirow{2}{*}{ Abortion period } & Below five months & 29 & 6.9 & & - & - & - \\
\hline & Above five months & 29 & 34.5 & 0.010 & 7.105 & 1.395 & 14.180 \\
\hline \multirow{2}{*}{ Abortion stage } & First parity & 30 & 20 & & - & - & - \\
\hline & More than one parity & 28 & 21.4 & 0.893 & 1.091 & 0.306 & 3.888 \\
\hline
\end{tabular}

from univariable logistic regression were further analyzed by multivariable logistic regression. $P<0.05$ was taken as significant.

\section{Results}

3.1. Logistic Regression Analyses of Reproductive Conditions Affecting Seropositivity in Cattle. The overall seroprevalence of Brucella infection in cattle was $4.9 \%$ while in a subpopulation of females aged $\geq 3$ years it was $6.1 \%$ (Table 2 ). An attempt was made to find out the association of the seropositivity with different reproductive status. By using heifer as reference category, univariable logistic regression analysis indicated significant differences and associations in pregnant and dry cows. There was, however, no significant difference and association of the seropositivity in lactating cows. Moreover, by using cows with zero parity as reference category, the result revealed that the risk increases as the parity number increases (Table 2 ). There were significant $(P<0.0001)$ differences among the stage of pregnancy with higher seroprevalence recorded in pregnant cows above or equal to five months. The multivariable logistic-regression model (Table 2) showed that parity status had significant association with cattle seropositivity to Brucella antibody. However, there was no significant association with reproductive status.

3.2. Association between Brucella Antibodies, Abortion Related Conditions and Calving Interval. Logistic regression analyses of abortion related factors such as previous history of abortion, abortion frequency (only once and more than one), abortion stage (at first parity and more than one parity), and abortion period (above/below five months) are summarized in Table 3. Significant differences and associations were observed between seropositivity and presence of abortion $(P=0.001 ; \mathrm{OR}=3.641)$. The impact of Brucella antibody on cattle reproductive performance was assessed by taking calving interval as one parameter (Table 4). The difference and association also proved as significant $(P=0.002, \mathrm{OR}=$ 4.964). 
TABLE 4: Univariable logistic-regression (LR) analyses of reproductive performance parameter (calving interval in months) with dependent Brucella seropositivity in female cattle in Western Tigray, North West Ethiopia. OR:odds ration, CI:confidence interval, October 2007 to February 2008.

\begin{tabular}{lcccccr}
\hline \multirow{2}{*}{ Calving interval } & \multicolumn{2}{c}{ CFT result } & \multirow{2}{*}{$P$-value } & OR & \multicolumn{2}{c}{ 95\% CI of OR } \\
& Cattle tested $(n)$ & Prevalence (\%) & & & & Upper \\
\hline$<15$ months & 49 & 10.2 & & & & \\
$\geq 15$ months & 61 & 36.1 & 0.002 & 4.964 & 1.716 & 14.363 \\
\hline
\end{tabular}

TABLE 5: Seroprevalence of brucellosis in human risk groups of Western Tigray, North Western Ethiopia, October 2007 to February 2008 .

\begin{tabular}{lccc}
\hline \multirow{2}{*}{$\begin{array}{l}\text { Vulnerable groups for } \\
\text { brucellosis }\end{array}$} & \multicolumn{2}{c}{ Number of samples } & \multirow{2}{*}{ Prevalence (\%) } \\
\hline Animal health workers & 7 & Female & \\
Butchers & 21 & 8 & 0 \\
Abattoir workers & 12 & - & 0 \\
Herdsmen & 185 & 13 & 1.5 \\
\hline Total & 225 & 21 & 1.2 \\
\hline
\end{tabular}

3.3. Brucellosis in Humans. Of the 246 human sera collected, 21 were from females and the rest were from males. No Brucella seroreactive case was identified from females (Table 5). Three seropositive samples (1.2\%) were found from males involved in livestock herding. Analysis of questionnaire results indicated that there was significant difference between those who removed retained fetal membrane and prevalence of brucellosis $(P=0.046)$. Moreover herdsmen who drink raw milk had $2.5 \%$ prevalence (Table 6 ).

\section{Discussion}

This cross-sectional study was designed to investigate the impact of Brucella infection on reproductive conditions in indigenous female cattle breeds and explore the presence of human seroreactors in Western part of Tigray. It has been previously shown that seroprevalence of bovine brucellosis is associated with the management and husbandry practices. District, herd size, production system, grazing system, and watering point were found to associate with bovine brucellosis [8]. In the current study, the overall seroprevalence of bovine brucellosis in breeding female cattle aged 3 years and above was found to be $6.1 \%(82 / 1,354)$.

Univariable and multivariable logistic regression analyses were performed to assess the impact of Brucella antibody presence on reproductive conditions of cows. Under the reproductive status parameters, small number of seroreactors was found in heifers. Taking heifer as a reference category, the univariable logistic analyses indicated that the odds ratio for seropositivity was higher in pregnant $(\mathrm{OR}=2.4)$ and dry cow $(\mathrm{OR}=2.3)$ than heifer or lactating cows. The finding of the association between parity number and seropositivity is inconsistent with Yilkal et al. [4]. It was suggested that sexually matured and pregnant cattle are more susceptible to Brucella infection than sexually immature
[19]. Presence of higher seropositive in cows above five month of pregnancy may also be due to the preferential localization of Brucella in the uterus in which allantoic fluid factors such as erythritol could stimulate the growth of Brucella and elevate in the placenta and fetal fluid from about the fifth month of gestation $[20,21]$. The association between abortion and seropositivity was interesting. The result not only indicates the significance of the disease but also confirms the skepticism of local farmers on the perceived benefits of barka breed, a breed traditionally meant for semi-intensive production system. This finding was in line with Radostits et al. [21] who stated that late abortion and premature or full-term birth of dead or weak calves predominated in pregnant animals with brucellosis. Brucellosis causes heavy economic lose in livestock producers that stem from abortion, loss of calves due to abortion and increasing calving intervals $[2,13]$. This is consistent with the present study that seropositive cows had relatively longer calving intervals than the seronegative ones $(P=0.002$; $\mathrm{OR}=4.964$ ).

In the human risk group, out of the 246 human serum samples only $3(1.2 \%)$ sera were seropositive. This paper is, to our knowledge, the first to report the existence of human seroreactors in the region. The risk groups tested were abattoir workers, animal heath personnel, butchers, and herdsmen. Positive sera were found only in herdsmen. Our result indicates that there was $1.3 \%(n=225)$ prevalence of brucellosis among the examined males. No female was found to react positively. This apparent variation in seroprevalence between sexes could probably be due to small female samples. This variation may also be explained due to the fact that in our study area the majority of the herding practice is carried out by males, which in turn might have contributed to high exposure to the infection.

Prevalence of brucellosis in man is largely influenced by the prevalence of the disease among domestic animals [19]. Brucellosis in humans is acquired from infected animals through direct contact or indirectly by ingestion of animal products [22]. Our study indicated that there was an association of seropositivity with the practice of removing of fetal membranes and consuming raw milk.

In conclusion, our study documented that brucellosis increased the calving interval and seropositivity was highly associated with abortion, all being at the center farmer's skepticism towards the cattle breed introduced to them. Proper hygiene and hygienic practices coupled with serological screening should improve the efforts to combat the disease transmission in livestock and its impact on reproduction of valuable cattle breeds. Despite the higher specificity of 
TABle 6: Association of Brucella seropositivity with some risk factors in humans of Western Tigray, North Western Ethiopia, October 2007 to February 2008.

\begin{tabular}{lcccc}
\hline Risk factors & Category level & $n$ & Prevalence (\%) & $P$-value \\
\hline \multirow{2}{*}{ Removal of retained fetal membrane } & No & 157 & 0 & 3.4 \\
& Yes & 89 & 0 & 0.046 \\
Drinking of raw milk & No & 124 & 2.5 & 0.120 \\
& Yes & 122 & 11 & 0 \\
Animal contacts & No & 235 & 1.3 & 0.871 \\
& Yes & & \\
\hline
\end{tabular}

CFT, numbers of human serum samples positive on the CFT for brucellosis were so low that no definite conclusion can be made. Due to the low numbers, confirmation of brucellosis through microbiology would be much comfortable. Though the finding in humans was in the low prevalence range, it is fairly reasonable to expect increasing human cases in future as there are several risk factors for the perpetuation and dissemination of the disease, thus avoiding contact with infected animals and consumption of their raw milk and milk products is of paramount importance. In the face of several potential risk factors to human infection, it would be reasonable to stimulate vaccination of heifers with $S 19$ or heifers and adults with RB51 vaccines. Equally important, teamwork between veterinary and human health personnel is of extreme importance to create awareness through educational campaigns among human risk groups.

\section{Authors' Contribution}

M. Haileselassie conceived the general research design, collected bovine sera, and participated in data analysis and interpretation. S.kalayou coordinated the study, participated in data analysis and drafted the paper, M. Kyule participated in designing the study, M. Asfaha coordinated human sera sampling, K. Belihu contributed to and refined the general research idea. All authors read and approved the final paper.

\section{Acknowledgments}

This project was funded by the regional bureau of agriculture and rural development. The authors would like to thank the staff of the Regional Animal Health Laboratory and National Veterinary Institute (NVI), Immunology laboratory for their all round technical assistance during serology. Many thanks are due to Dr. Berhanu Hadush for his contribution in the field work. Special thanks go to Mr. Mussie Gezu, Dr. Kelali Adhana, Dr. Fisseha Abnet, and Professor S. K. Khar for their valuable comments, and Mr. Hailay Kidanu for his material support and Mrs. Merhawit Hadush for her devotion while drafting the paper.

\section{References}

[1] J. J. McDermott and S. M. Arimi, "Brucellosis in subSaharan Africa: epidemiology, control and impact," Veterinary Microbiology, vol. 90, no. 1-4, pp. 111-134, 2002.
[2] M. Bekele, B. Demelash, A. Fufa, A. Regassa, J. Godfroid, and E. Skjerve, "Seroprevalence of brucellosis and its contribution to abortion in cattle, camel, and goat kept under pastoral management in Borana, Ethiopia," Tropical Animal Health and Production, vol. 43, pp. 651-656, 2010.

[3] B. Gebretsadik, B. Kelay, and A. Yilkal, "Seroepidemiological investigation of bovine brucellosis in the extensive cattle production system of Tigray region of Ethiopia," International Journal of Applied Research in Veterinary Medicine, vol. 5, no. 2, pp. 65-71, 2007.

[4] A. Yilkal, M. Bayleyegn, Z. Karl-Hans, and T. Azage, "The epidemiology of bovine brucellosis in intra and peri-urban dairy production systems in and around Addis Ababa, Ethiopia," Tropical Animal Health and Production, vol. 46, pp. 217-224, 1998.

[5] B. Abay, M. Bayleyegn, A. Yilkal, and Y. Laikemariam, "Bovine brucellosis; sero- epidemiological study in selected farms and ranches in southeastern Ethiopia," Bulletin of Animal Health and Production in Africa, vol. 48, pp. 13-17, 2000.

[6] T. Kebede, G. Ejeta, and G. Ameni, "Seroprevalence of bovine brucellosis in smallholder dairy farms in central Ethiopia (Wuchale-Jida District)," Revue de' Elevage et Medicine Veterinaire des Pays Tropicaux, vol. 159, pp. 3-9, 2008.

[7] I. Nuraddis, B. Kelay, L. Fikre, and B. Merga, "Sero-prevalence of bovine brucellosis and its risk factors in Jimma zone of Oromia Region, South-western Ethiopia," Tropical Animal Health and Production, vol. 42, no. 1, pp. 35-40, 2009.

[8] M. Haileselassie, S. Kalayou, and M. Kyule, "Serological survey of bovine brucellosis in barka and arado breeds (Bos indicus) of Western Tigray, Ethiopia," Preventive Veterinary Medicine, vol. 94, no. 1-2, pp. 28-35, 2010.

[9] A. Kassahun, Epidemiology of brucellosis in cattle and its seroepidemiology in animal health professionals in Sidama zone, Southern Ethiopia, M.S. thesis, Faculty of Veterinary Medicine, Addis Ababa University, Debre Zeit, Ethiopia, 2004.

[10] T. Tadele, Seroprevalence study of bovine brucellosis and its public health significance in selected sites of Jimma zone, Western Ethiopia, M.S. thesis, Faculty of Veterinary Medicine, Addis Ababa University, Debre Zeit, Ethiopia, 2004.

[11] H. Mussie, Seroprevalence study of brucellosis in cattle and human in Bahirdar milk shed, M.S. thesis, Faculty of Veterinary Medicine, Addis Ababa University, Debre Zeit, Ethiopia, 2005.

[12] J. E. O. Rege, "The state of African cattle genetic resources. Classification framework and identification of threatened and extinct breeds," Animal Genetic Resources Information Bulletin, no. 25, pp. 1-25, 1999.

[13] S. Olsen and F. Tatum, "Bovine brucellosis," Veterinary Clinics of North America: Food Animal Practice, vol. 26, no. 1, pp. 1527, 2010 . 
[14] M. Thrusfield, Veterinary Epidemiology, Blackwell Science, London, UK, 3rd edition, 2005.

[15] C. Staak, F. Salchow, and N. Denzin, Practical Serology: From the Basic to the Testing, Bundesinstitut fiir Gesundheitlichen verbaucherschutz and Veterinarmedizin (BgVV): Deutsche Gesellschaft fiir Technische Zusammenarbeit (Gtz) Miinchen: Urban and Vogel, Munich, Germany, 2000.

[16] OIE, “Ovine epididymitis (B. ovis)," in Manual of Standards for Diagnostic Test and Vaccine, pp. 467-474, Office International des Epizooties (OIE), Paris, France, 2000.

[17] OIE, "Bovine brucellosis," in Manual of Diagnostic Tests and Vaccines for Terrestrial Animals, pp. 409-438, Office International des Epizooties (OIE), Paris, France, 5th edition, 2004.

[18] Statistical Package for Social Science, "SPSS for window (Version 11.5)," Chicago, Ill, USA, 2002.

[19] M. K. Omer, T. Assefaw, E. Skjerve, T. Tekleghiorghis, and Z. Woldehiwet, "Prevalence of antibodies to brucellosis species risk factors related to high risk occupational groups in Eritrea," Epidemiology and Infection, vol. 129, no. 1, pp. 85-91, 2002.

[20] J. W. Coetzer and R. C. Tustin, Infectious Diseases of Livestock, vol. 3, South Africa Oxford University press, 3rd edition, 2004.

[21] O. M. Radostits, C. C. Gay, K. W. Hinchcliff, and P. D. Constable, Veterinary Medicine: A Text Book of the Diseases of Cattle, Sheep, Pigs, Goats and Horses, Saunders, Philadelphia, Pa, USA, 10th edition, 2007.

[22] P. U. Acha and B. Szyfers, Zoonosis and Communicable Disease Common to Man and Animals, Pan America Health Organization, Washington, DC, USA, 3rd edition, 2001. 

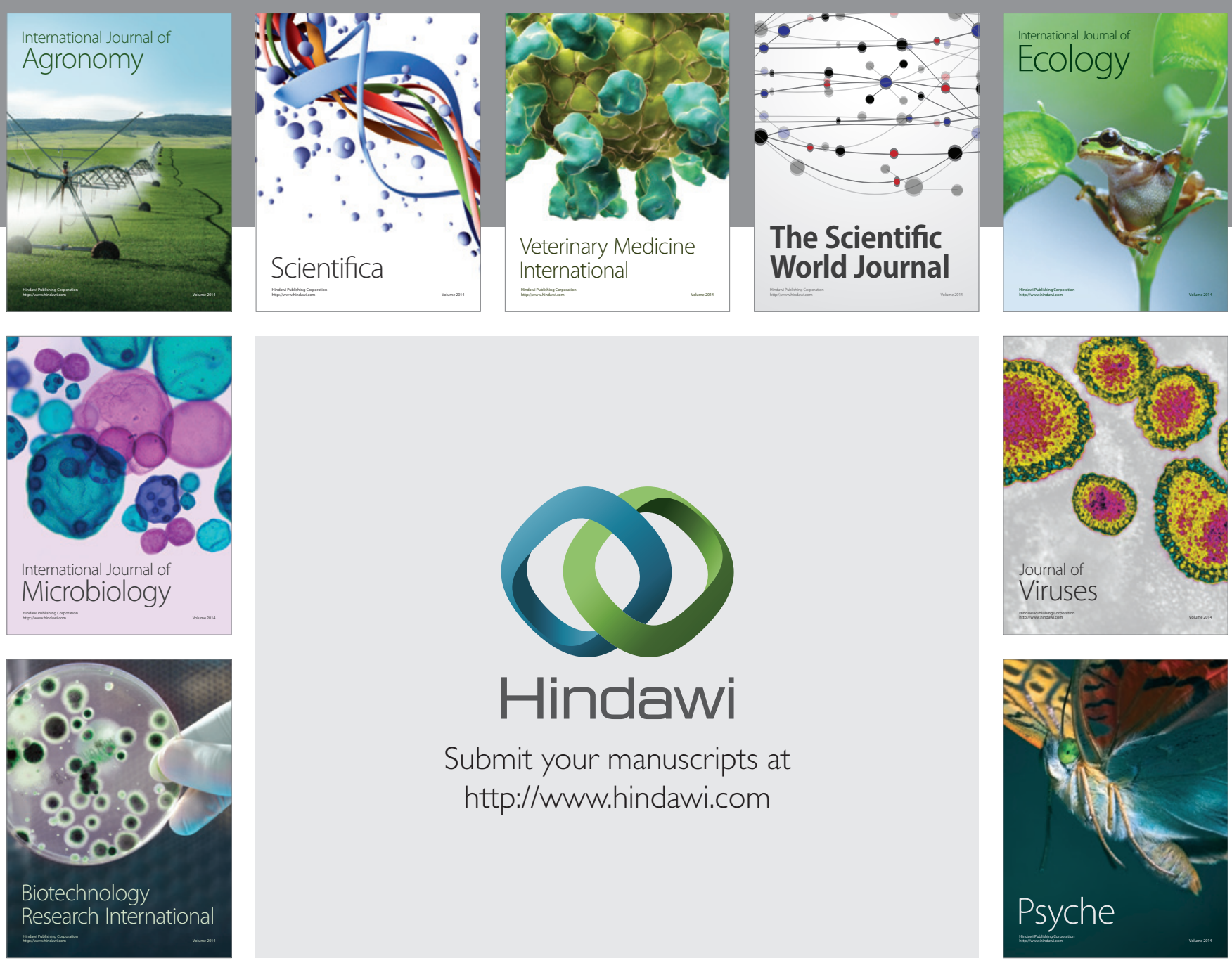

Submit your manuscripts at

http://www.hindawi.com
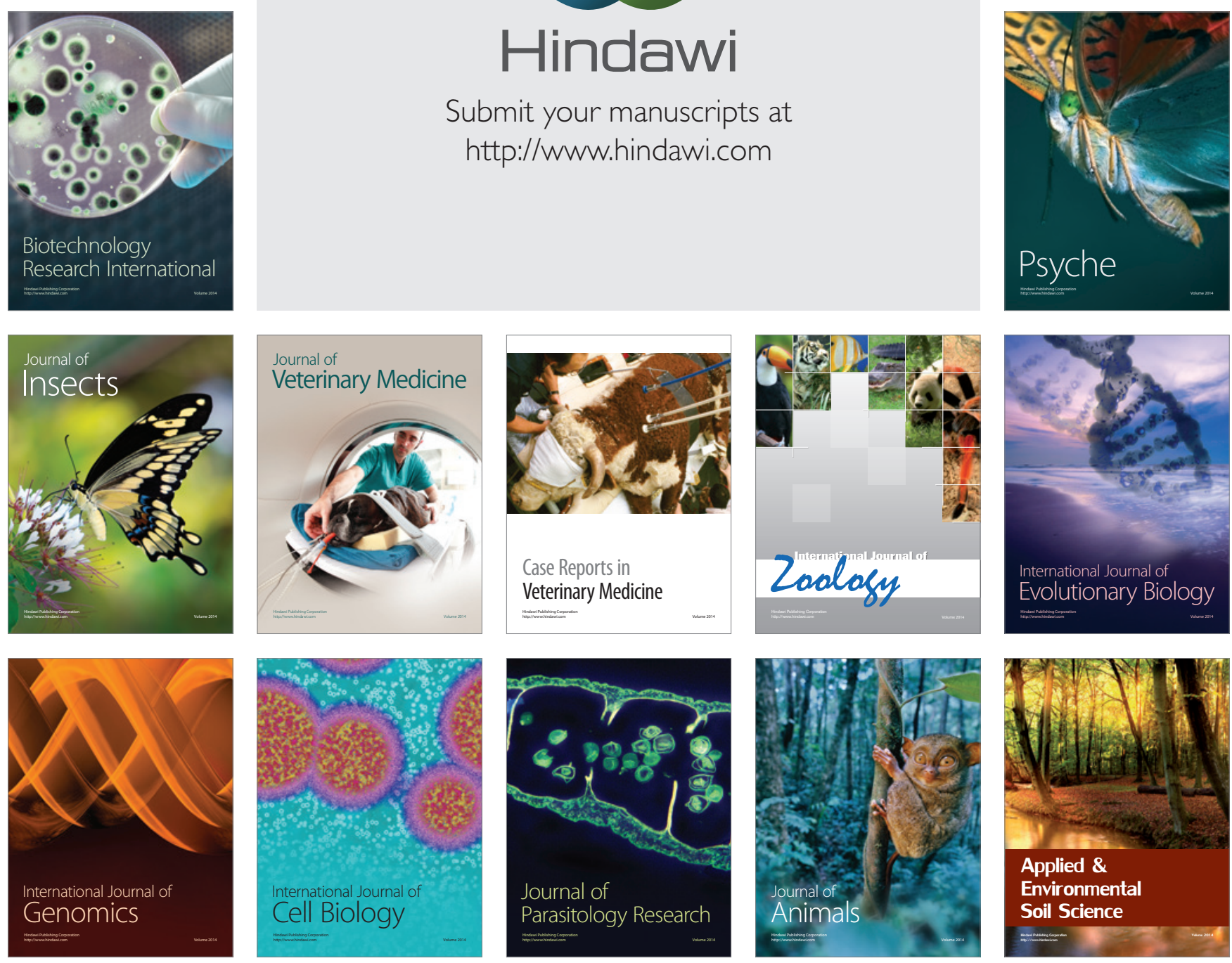